DR GISELA HELFER (Orcid ID : 0000-0003-0634-4683)

Article type : Review Article

\title{
A unifying hypothesis for control of body weight and reproduction in seasonally breeding \\ mammals
}

Gisela Helfer ${ }^{1}$, Perry Barrett ${ }^{2}$ and Peter Morgan ${ }^{2}$

${ }^{1}$ School of Chemistry and Biosciences, University of Bradford, Richmond Road, Bradford, BD7 1DP,

UK

${ }^{2}$ Rowett Institute of Nutrition and Health, University of Aberdeen, Foresterhill, Aberdeen AB25 2ZD,

UK

\section{Correspondence:}

Gisela Helfer

School of Chemistry and Biosciences, University of Bradford

Richmond Road

Bradford

BD7 1DP, UK

E-mail: g.helfer@bradford.ac.uk

This article has been accepted for publication and undergone full peer review but has not been through the copyediting, typesetting, pagination and proofreading process, which may lead to differences between this version and the Version of Record. Please cite this article as doi: $10.1111 /$ jne. 12680

This article is protected by copyright. All rights reserved. 
Short title: Seasonal control of body weight and reproduction

Key words: photoperiod, season, pars tuberalis, tanycyte, melatonin, neurogenesis, neuroendocrinology, thyroid hormone, retinoic acid

\section{Abstract}

Animals have evolved diverse seasonal variations in physiology and reproduction to accommodate yearly changes in environmental and climatic conditions. These changes in physiology are initiated by changes in photoperiod (daylength) and are mediated through melatonin which relays photoperiodic information to the pars tuberalis of the pituitary gland. Melatonin drives thyroid stimulating hormone transcription and synthesis in the pars tuberalis which in turn regulates thyroid hormone and retinoic acid synthesis in the tanycytes lining the third ventricle of the hypothalamus. Seasonal variation in central thyroid hormone signalling is conserved among photoperiodic animals. Despite this, different species adopt divergent phenotypes to cope with the same seasonal changes. A common response amongst different species is increased hypothalamic cell proliferation/neurogenesis in short photoperiod. That cell proliferation/neurogenesis may be important for seasonal timing is based on 1) the neurogenic potential of tanycytes, 2) the fact that they are the locus of striking seasonal morphological changes and 3) the similarities to mechanisms involved in de novo neurogenesis of energy balance neurons. We propose that a fall in hypothalamic thyroid hormone and retinoic acid signalling initiates localised neurodegeneration and apoptosis which leads to a reduction in appetite and body weight. Neurodegeneration induces compensatory cell proliferation from the neurogenic niche in tanycytes and new cells are born under short photoperiod. Since these cells have the potential to differentiate into a number of different neuronal phenotypes, this could provide a mechanistic basis to explain the seasonal regulation of 
energy balance as well as reproduction. This cycle can be achieved without changes in thyroid hormone/retinoic acid and explains recent data from seasonal animals held in natural conditions. However, thyroid/retinoic acid signalling are required to synchronise the cycles of apoptosis, proliferation and differentiation. Thus, hypothalamic neurogenesis provides a framework to explain diverse photoperiodic responses.

\section{Introduction}

Biological time-keeping mechanisms exist in all organisms and these are essential to synchronising the temporal order of intrinsic biochemical processes and physiology with the daily changes in environmental conditions. Timing systems are also important to ensure that animals are appropriately synchronised and adapted to the yearly changes in environmental and climatic conditions. Seasonal cycles in reproductive competence, growth, energy balance and metabolism, migration, moulting and hibernation are among these adaptations. Although there are a number of extrinsic signals, such as temperature variations or food availability, that birds and mammals can use to track seasonal time the most important time cue to co-ordinate seasonal responses by animals living at temperate latitudes appears to be photoperiod (day length) (1).

While photoperiod is an important cue, the nature of the response to a given photoperiod depends on the species. Thus, for sheep and deer, shortening photoperiod is associated with increased reproductive competence, which means that the 'breeding season' is during the autumn, allowing offspring to be born 6 months later in the warming days of spring when food availability is optimal $(2,3)$. The shortening photoperiod is also associated with reduced food intake and decreased body weight (fatness) (4). By contrast, for Siberian (also known as Djungarian hamsters, Phodopus sungorus) and Syrian hamsters (Mesocricetus auratus) reproductive competence is associated with long photoperiod (the opposite to sheep), yet they exploit different strategies for energy balance. Siberian hamsters decrease food intake, body weight and body fat in response to short photoperiod,

This article is protected by copyright. All rights reserved. 
whereas Syrian hamsters increase body weight and fatness in response to the same photoperiod (5, 6). Thus, different species adopt different strategies to cope with the same seasonal changes and so fundamental questions for seasonal biologists are: 1) what are the common pathways in the photoperiod response, 2) where does the divergence in response occur and 3) what are the mechanisms involved? Here we will explain how the photoperiodic signal is 'read' and translated into a biochemical signal by the brain to result in the desired physiological output and provide a unifying hypothesis as a theoretical basis to explain the seasonal control of body weight and, potentially, reproduction.

\section{Melatonin is the photoperiodic message}

For mammals, melatonin is a key endocrine signal which relays photoperiodic information to the neuroendocrine system. Melatonin is produced by the pineal gland only during the night and thus translates the length of the night into a neurochemical signal. The importance of melatonin in photoperiodic animals was shown by pinealectomy experiments and duration signals in both sheep and hamsters $(7,8)$.

Nonetheless there are also melatonin-independent components to the seasonal response. Photorefractoriness is characteristic of seasonal species, where the reproductive axis undergoes a spontaneous reactivation if animals are maintained on a fixed (unchanged) photoperiod for an extended period of time. For short day breeders, like sheep, this means that extended exposure to long photoperiod triggers a spontaneous switch from anoestrus to oestrus (2). Whereas long day breeders such as small rodents (e.g. Siberian hamsters) become refractory to short photoperiod and default back to a long day phenotype, reflected by reproductive competence and change in body weight (6). Nightly melatonin secretion during this spontaneous refractory switch continues to signal ambient day/night length (9). In nature this intrinsic photorefractory response ensures a timely start of the repdroductive season in spring. Thus, the photorefractory response shines a light on a

This article is protected by copyright. All rights reserved. 
melatonin-independent component of a long-term (circannual) timing system. Indeed, for some longer living species there is clear evidence of a circannual timing system that can function without overt changes in melatonin. Such circannual rhythms were first described in golden-mantled ground squirrels that were held on a fixed photoperiod and temperature, yet they showed annual cycles in food intake, body weight and hibernation (10). For a number of long-lived species circannual cycles are now well-documented $(11,12)$, but even species with short life-spans retain elements of circannual rhythms in their seasonal cycle (13).

\section{The pars tuberalis as a key intermediary site for photoperiod}

The pars tuberalis (PT) of the pituitary, the anterior lobe of the pituitary stalk that connects the hypothalamus and the posterior pituitary, has been identified as a key site involved in the regulation of seasonality across birds and mammals. A key step forward in developing our understanding of the role of melatonin in the mammalian photoperiodic response was the identification of melatonin receptors on the PT (14). Early studies using auto-radiographic mapping of melatonin binding identified the PT as the only consistent site of $2-{ }^{125}$ I- melatonin binding in a wide range of seasonally breeding mammalian species (8). Subsequent cytochemical studies revealed how thyroid stimulating hormone (TSH) immunoreactivity altered in response to photoperiod in the PT of the hamster (1517). The functional relevance of these findings were put into context by the pioneering work of Yoshimura and co-workers. They identified that TSH transcription and synthesis is photoperiodically regulated in the PT in quail and that this in turn regulates thyroid hormone synthesis in the hypothalamus to regulate reproduction $(18,19)$. More recent studies have provided evidence of how the PT has intrinsic clock-like properties and may act as a circannual timer (20), where transcription factors and coactivators, such as TEF, SIX1 and EYA3 drive TSH $\beta$ gene expression to link melatonin to a local circadian clock and drive the photoperiodic control (21).

This article is protected by copyright. All rights reserved. 


\section{The pars tuberalis as an intermediate between melatonin and thyroid hormone action}

A considerable body of evidence supports the idea that localised thyroid hormone metabolism is a critical and common neuroendocrine component of the photoperiodic response in both birds and mammals. In mammals, melatonin acts through melatonin receptors located on the PT cells to regulate TSH ( $\alpha$ - and $\beta$-sub-unit gene and protein expression). Evidence for this came from experiments in Siberian hamsters where pinealectomy was shown to block short day-induced suppression of both TSH $\alpha$ and $\beta$ immunoreactivity as well as gene expression for both TSH $\alpha$ and $\beta$ in the PT (17). Additionally, the effects of short photoperiod on TSH immunoreactivity in the PT was mimicked by melatonin injections in hamsters held in long day (16). Subsequent studies in sheep and the F344 rat have shown that gene expression of the $\alpha$ and $\beta$ sub-units of TSH are similarly strongly regulated by photoperiod, with high expression in long day and low expression in short day (22-24). It has been inferred that TSH acts in a paracrine manner to activate TSH receptors located in specialised glial cells, the tanycytes, around the third ventricle of the hypothalamus (25). Consistent with a unique physiological role for TSH derived from the PT it has been demonstrated that PT-TSH is distinctly glycosylated relative to TSH from the pars distalis, and that PT-specific TSH is detectable in circulation, but does not stimulate the thyroid gland (26).

Alongside TSH, a further peptide hormone has been shown to play a role in the photoperiodic response in F334 rats (27). Neuromedin $\mathrm{U}$ (NMU) is expressed in the same cells in the PT as TSH (28) and is under strong photoperiodic regulation (29). NMU appears to be an important mediator of the photoperiodic response in the rat, but whether it has a photoperiodic role in other species remains to be determined.

This article is protected by copyright. All rights reserved. 


\section{Tanycytes are the mediators of the photoperiodic response}

Both PT-derived TSH and NMU act through their G-protein coupled receptors TSH-R and $\mathrm{NMU}_{2}$, respectively, located on the tanycytes surrounding the third ventricle of the hypothalamus. Recently, the tanycytes have emerged as an integral part of the hypothalamic networks that control body weight, appetite regulation and energy balance $(30,31)$. Tanycytes extend into hypothalamic nuclei closely associated with homeostatic appetite regulation and act as gatekeepers for peripheral signals, such as leptin, to regulate metabolic control $(30,31)$. Tanycytes exhibit high levels of structural plasticity and importantly, it is photoperiod that strongly affects the structural organisation of tanycytes. In long photoperiod, tanycytes are densely distributed around the third ventricle of the hypothalamus forming long radial processes, visualised by immunolabelling for vimentin, which project into the hypothalamic areas controlling body weight regulation. Immunolabelling for vimentin is markedly decreased in short photoperiod (32-35) implying profound change in both structure and function of these radial projections.

In the seasonal context, tanycytes are particularly important because they regulate hypothalamic thyroid hormone through the expression of type 2 (Dio2) and 3 (Dio3) deiodinases. Dio2 and 3 are key enzymes that regulate thyroid hormone bioactivity. Dio2 converts the prohormone thyroxine (T4) by phenolic ring deiodination to the bioactive triiodothyronine (T3), whereas Dio3 converts T4 into biologically inactive rT3 and inactivates T3 by tyrosyl ring deiodination to diiodothyronine (T2) (36). Thus, the expression of Dio2 and Dio3 enzymes provide a key molecular step to regulate the local hypothalamic availability of T3. Photoperiod-regulated changes in Dio2 and Dio3 mRNA expression have been shown in a number of species and seem to be a conserved feature among seasonal animals, however the relative importance of Dio2 and Dio3 gene expression appears species-specific $(22,23,37-43)$. TSH infusion into the third ventricle of the hypothalamus has been shown to increase Dio2 expression in quail, sheep and F344 rats, but to also inhibit Dio3 in F344 rats $(19,24,27)$. Importantly, NMU infusion into the third ventricle also increases Dio2 (but not Dio3)

This article is protected by copyright. All rights reserved. 
expression in the tanycytes of F344 rats (27) indicating that NMU is also involved in regulating T3 availability in the rat. The net effect of these changes in Dio2 and Dio3 gene expression predicts that T3 levels in the mediobasal hypothalamus are increased under long day relative to short day in photoperiod-sensitive species. Overt increase in hypothalamic T3 levels in response to long day has been observed in the quail (18), whereas in F344 rats changes in T3 in response to long photoperiod are subtler, despite large changes in Dio2 and Dio3 expression in the tanycytes (22). This in part may reflect the markedly different photoperiodic responses of quail and mammals. Reactivation of the reproductive axis in quail held on short day can be induced by only a single light pulse during a photo-sensitive period (18), whereas mammalian responses to photoperiod require sustained stimulus over several weeks $(24,39)$.

Elevated hypothalamic levels of T3 are known to inhibit thyrotrophin-releasing hormone (TRH) expression in the paraventricular nucleus (PVN) as part of the negative feedback neuroendocrine loop of the thyroid hormone axis (44), yet TRH expression in neither Siberian hamsters nor F344 rats are affected by photoperiod $(22,45)$. Thus, these data indicate that any changes to T3 levels in the hypothalamus as part of the photoperiodic response do not disturb the TRH-TSH-T3 (PVN-pituitarythyroid gland) neuroendocrine axis. More likely is that the changes in T3 in response to photoperiod are discrete, localised and tightly regulated. Part of this tight regulation is likely to involve other components of the thyroid regulatory system, which are also under photoperiodic control. These include the thyroid hormone transporter monocarboxylate 8 (MCT-8) and organic anion transporter family member $1 C 1$ (Oatp1c1), which can rapidly regulate thyroid hormone levels $(46,47) . M C T-8$ is more highly expressed in short photoperiod in both the Siberian hamster and the F344 rats $(22,40$, 48), and in the F344 rats Oatp1c1 is more highly expressed in long photoperiod (22). This divergent expression pattern emphasises the fact that photoperiodic regulation of thyroid hormone metabolism and its relationship to physiological outcomes is more complex than a simple on/off switch related solely to T3 levels in mammals.

This article is protected by copyright. All rights reserved. 


\section{The role of the retinoic acid system}

A microarray analysis of photoperiod regulated gene expression in the hypothalamus of F344 rats has provided clear evidence of the wider complexity of the photoperiodic response in mammals (22). The F344 rat is one of the few rat strains that has remained sensitive to changes in daylength with strong photoperiod-dependent changes in body weight, food intake and reproductive status. It has therefore provided a useful model given the molecular methods available for the study of rats, relative to more mainstream seasonal animals (49).

One of the more prominent photoperiod-regulated signalling pathways identified by microarray analysis was retinoic acid, a metabolite of Vitamin A (22). Like thyroid hormone signalling many components involved in the retinoic acid pathway are expressed in tanycytes and adjacent areas and are strongly regulated by photoperiod. In F344 rats, this includes retinoic acid signalling genes and proteins involved in uptake (Stra6, Ttr and Crbp1), synthesis (Raldh1, Raldh2), receptor response (RAR) and ligand clearance (Crapb1 and Cyp26B1) $(29,50)$. Evidence for retinoic acid signalling genes has also been found in the Siberian hamster. Crpb1, Crabp2, RAR and $R X R$ are all strongly regulated by photoperiod, with high expression in long days and much reduced expression in short days (5153). Through a combination of melatonin injections, pinealectomy and testosterone injections it has been shown that these changes are melatonin-dependent and not secondary consequences of changes in reproductive status $(29,51)$. In rats there is evidence that retinoic acid signalling lies downstream of thyroid hormone signalling Hypothalamic expression of the Raldh1 gene, the rate limiting enzyme for retinoic acid synthesis, is increased following peripheral injection of thyroid hormone (T4) in vivo (54). Consistent with this, T3 increases Raldh1 expression in neonatal hypothalamic explants from rats ex vivo (54). In F344 rats, the large changes in Raldh1 mRNA seen in response to photoperiod leads to an increase in tissue levels of retinoic acid in the hypothalamus (29).

This article is protected by copyright. All rights reserved. 
One of the hypothalamic actions of retinoic acid is to increase gene expression of the retinoic acid responder 2 (Rarres2) gene, which encodes for the protein chemerin (35). Chemerin is an inflammatory chemokine, which has been associated with inflammation, adipogenesis and angiogenesis (55). It has also been postulated to play a role in the regulation of energy balance as it is highly expressed in white adipose tissue, which is in direct proportion to the level of adiposity. Consistent with this, circulating chemerin levels are positively correlated with $\mathrm{BMI}$ in humans (55). Evidence for a neuroendocrine role for chemerin has come from F344 rats where intracerebroventricular administration of chemerin into the third ventricle of the hypothalamus alters food intake and body weight (35). Chemerin (Rarres2) transcript and its receptors Cmklr1 and Ccrl2 are highly expressed in tanycytes and adjacent areas and are under strong photoperiod regulation with higher levels in long day relative to short day. Interestingly, chemerin seems to play a role in hypothalamic cellular remodelling because central chemerin administration increases the expression of vimentin, an intermediate filament protein expressed by tanycytes and results in morphological changes to the hypothalamus by increasing immunoreactive Vimentin labelling of tanycytes (35).

Despite the clear evidence for a role of retinoic acid in photoperiod signalling in the hypothalamus of both the F344 rat and Siberian hamster, there are no data available to indicate a role for any retinoic acid signalling genes in sheep. Indeed, it is noteworthy that in a recent RNAseq study in sheep, no retinoic acid related genes were shown to be differentially expressed between long day versus short day or between thyroidectomised animals on long day relative to controls (56). This apparent difference between sheep and rodents needs to be verified by other techniques, but if substantiated this may be an interesting point of distinction between long day and short day breeders.

This article is protected by copyright. All rights reserved. 


\section{Other photoperiodic regulated players are expressed in tanycytes}

Tanycytes have been discussed as key determinants of long-term seasonal changes in energy balance mainly because of their role in transport and regulation of thyroid hormone and retinoic acid availability (57), but several other components expressed in tanycytes and surrounding hypothalamic areas have been shown to change in response to photoperiod emphasising that other pathways are potentially important to this process.

\section{The Wnt signalling pathway}

The $W n t / \beta$-catenin signalling is another photoperiod-regulated pathway first identified by microarray analysis of F344 rat hypothalami (21), with expression being localised to the tanycytes $(27,29,58)$. More recently photoperiod-regulated Wnt signalling genes have also been shown in the hypothalamus of Siberian hamsters (59). A close relationship between the retinoic acid and Wnt/ $\beta$ catenin pathways has been demonstrated in the hippocampus where members of the Wnt gene family are downstream components of the retinoic acid pathway (60). However, in the hypothalamus such a direct relationship seems unlikely, since intracerebroventricular injection of retinoic acid into the hypothalamus of F344 rats failed to alter Wnt-related gene expression (35). Additionally, intracerebroventricular injection of TSH, which should increase the activity of the retinoic acid pathway via thyroid hormone (54), also did not alter Wnt pathway genes (27).

In the F344 rat, PT-derived NMU appears to be one of the main regulators of Wnt signalling in the tanycytes, because intracerebroventricular injection of NMU rapidly increases the expression of sFrp2 and Dkk3 (27). These are important regulators of the canonical Wnt pathway (61), providing evidence for an additional (non-TSH) mechanism through which PT-derived signals can synchronise changes in tanycyte function involved in photoperiodic regulation of seasonal physiology.

This article is protected by copyright. All rights reserved. 


\section{G-protein coupled receptor 50}

A further component that is noteworthy in the context of the photoperiodic regulation is the $G$ protein coupled receptor 50 (GPR50). GPR50 is highly expressed in the hypothalamus, specifically in tanycytes. It is also expressed in the PT of sheep, hamster, rat and mouse $(52,62)$ and has been investigated owning to its high sequence similarity to melatonin receptors. Despite its homology to melatonin receptors it does not bind melatonin $(63,64)$ and a ligand has yet to be identified. GPR50 mRNA is down-regulated in Siberian hamsters held in short photoperiod $(52,65,66)$ but remains low in refractory hamsters (66). While this might indicate that GPR50 is not required for the transition from a short day to long day phenotype and in the absence of a ligand the function of GPR50 remains elusive, a role in seasonal adaptation is still likely given that GPR50 knockout mice show an increased Dio2 expression in tanycytes (67) .

\section{Epigenetics}

Epigenetic changes, such as DNA methylation and histone acetylation, have also been shown to be part of the seasonal timing switch (68). DNA methylation is increased in long photoperiods in the Siberian hamster and this seems to be linked to reproductive competency $(69,70)$. DNA methylation via Dnmt3b is regulated by photoperiod and melatonin and takes place in the promoter region of Dio3 indicating that it is a critical component of the seasonal time measurement (69). Furthermore, seasonal variations in histone acetylation have been shown in Siberian hamster and F344 rats (71, 72). Hdac 4 and 6 are class II histone deacetylases which repress transcription by deactylated histone proteins. Genes for these enzymes are photoperiodically regulated in tanycytes of F344 rats with high expression under long day relative to short day. Importantly, these have the ability to modulate thyroid hormone and retinoic acid signalling pathways in tanycytes (71). Additionally, TSH induces Hdac4 expression in tanycytes of F344 rats (71) and it is therefore likely that epigenetic 
modifications occur as intermediate steps between PT-derived TSH and thyroid and retinoic acid signalling in the tanycytes. A recent study in sheep further highlights the PT as a key region for epigenetic changes. The histone methyltransferases Suv39HS and EZh2 and the transcriptional regulator EYA3, involved in histone modification, are strongly regulated by photoperiod in the PT and this seems to be independent of thyroid hormone (56). Hence, it remains to be investigated whether these PT-expressed genes control rege regulation directly in tanycytes.

\section{Inflammatory markers}

Interestingly, epigenetic regulation is linked to inflammation because HDACs can modulate the NF$\mathrm{KB}$ inflammatory signalling pathway in the hypothalamus. This has been shown in primary hypothalamic tanycyte cultures from F344 rats where HDAC4/5/6 inhibition induces Nfkb1 mRNA (71) but seasonal epigenetic alterations have also been confirmed in the immune system in Siberian hamsters (73). Additionally, $N f k b 1$ transcript is strongly upregulated in short day in F344 rats indicating that inflammatory signals may have the potential to regulate gene expression in short photoperiod (71). This is noteworthy, because inflammatory signalling in the brain is generally considered as a pathophysiological response rather than as a modulator of the physiological state of the healthy brain. Nfkb1 is the second inflammatory gene that is photoperiodically regulated in tanycytes, next to the aforementioned inflammatory chemokine chemerin (Rarres2) (35). The idea that inflammatory signals in the hypothalamus respond to photoperiod has been reported before (74) and it is therefore tempting to speculate that inflammatory markers may contribute to the photoperiodic response, potentially downstream of retinoic acid signalling given that acute retinoic acid injections into the third ventricle of the hypothalamus increases a number of inflammatory pathways (35). However, a recent study in Siberian hamsters was unable to show a photoperiodic difference in TNF $\alpha$ and Interleukin 16 in the hypothalamus, despite marked photoperiodic changes in the spleen (75). Thus, it remains to be established whether only a few specific inflammatory 
chemokines and cytokines, rather than a broader range of inflammatory mediators, are involved in the seasonal response.

\section{Orchestration response}

While the PT/tanycyte switch, involving TSH driven changes in Dio2 and Dio3 expression, is now recognised as a strongly conserved photoperiodic mechanism in birds and mammals (76), a recent study has raised major questions about how this mechanism relates to seasonal changes in physiological outcomes under natural conditions. A study by Petri et al. monitored the changes in hypothalamic gene expression in Siberian hamsters held under natural photoperiod from birth over two consecutive years (48). The study uncovered how the relationship between seasonal cycles in body weight and changes in thyroid, retinoic acid signalling and other tanycyte expressed genes (nestin, vimentin) can be dissociated. Over the first cycle, both Dio2 and Crbp1 expression in tanycytes decrease prior to any fall in body weight (Figure 1). Dio3 levels increase as body weight starts to fall, which would accentuate a decline in hypothalamic T3, initiated by reducing Dio2. However, over the second cycle, body weight increases prior to any significant rise in either Dio2 or Crbp1 (Figure 1). These data clearly demonstrate that the photoperiodic body weight response in Siberian hamsters is not driven by the absolute levels of thyroid hormone and retinoic acid under natural conditions. Instead it seems more likely that the changes in T3 and retinoic acid levels serve to synchronise cycles of energy balance and body weight controlled by other endogenous processes.

All of this underlines the importance of thyroid hormone metabolism to the seasonal body weight response, but also points to the importance of factors/processes other than hypothalamic T3 in driving the seasonal body weight responses under natural photoperiod. Clearly temporal organisation is a key element for the function of each gene, but it is also important to note that in the Petri et al. experiments, hamsters were housed outside in natural photoperiod and ambient temperatures (48).

This article is protected by copyright. All rights reserved. 


\section{Linking thyroid hormone signalling to energy balance}

The arcuate nucleus is an important integrative centre for the regulation of energy balance and thus an obvious question is its role in the seasonal cycles of food intake and body weight. AgRP neurons, which co-express NPY, are a key cluster of neurons, which increase food intake and body weight when activated. These neurons are counter-balanced by a cluster of POMC neurons, which inhibit food intake and reduce body weight (77). They are regulated by leptin, which is taken up through the fenestrated capillaries of the median eminence and is delivered to the arcuate nucleus via the tanycytes (78). Until recently, it was generally assumed that POMC is exclusively expressed in hypothalamic neurons, however, recent studies have shown that POMC mRNA and protein is also expressed in tanycytes in seasonal and non-seasonal rats $(23,79,80)$. These findings highlight how the tanycytes are an important route in the regulation of the activity of the AgRP/NPY and POMC neurons. Thus tanycyte-derived thyroid hormone has the potential to influence these arcuate nucleus energy balance genes by a similar route.

Nevertheless, while thyroid hormone is known to regulate energy balance and increase mitochondrial proliferation in AgRP/NPY neurons (81), no consensus has emerged about the relationship between the effects of photoperiod (and hence T3) and hypothalamic expression of energy balance genes (AgRP, NPY and POMC). Results from a number of studies and species including, hamsters, F344 rats and sheep have failed to identify a consistent pattern of gene expression responses that might explain the role of arcuate nucleus energy balance genes in the seasonal body weight response $(79,82-85)$. From this it is generally accepted that the relationship between photoperiod (and T3) and the genes involved in energy balance is neither direct, nor simple.

This article is protected by copyright. All rights reserved. 


\section{Neurogenesis as a common response}

A common response in seasonal mammals which provides a potentially important link between thyroid hormone/retinoic acid signalling and physiological outcome is cell proliferation/neurogenesis. Hypothalamic neurogenesis has been shown in a number of species, but only a few studies have investigated photoperiodic regulation of proliferative activity in seasonal animals (86) (Table 1). An early study in Syrian hamster showed that more hypothalamic cells are labelled with $\mathrm{BrdU}$ in animals exposed to short days relative to long days, which suggests increased proliferation under the former (87). This study suggested that there is increased proliferation of new cells in the hypothalamus under short day conditions. Subsequent studies in sheep have similarly shown that there is a greater number of BrdU labelled cells in the hypothalamus of animals exposed to short relative to long days $(88,89)$. Furthermore, L-dopachrome tautomerase (Dct), a tanycytic marker implicated in the control of progenitor cell proliferation, is regulated by photoperiod and thyroid hormone in sheep (90). Likewise, using Ki67 labelling, an immunocytochemical measure of cell proliferation, it has been shown that more cells are immunopositive for $\mathrm{Ki} 67$ in the hypothalamus of the F344 after exposure to short relative to long days (50) and this increased proliferative response in short days has been confirmed by BrdU labelling in F344 rats (Helfer, Morgan unpublished). Importantly, a recent study has shown that hypothalamic cell proliferation is dependent on melatonin in sheep (91). Recent studies sugest other interesting markers, such as Prss56, maybe useful in studying cell proliferation in seasonal animals (92). Together these data indicate that increased cell proliferation is another common response to short photoperiod in both long and short-day breeders (Table 1). It is well known that the tanycytes, which express many photoperiodically regulated genes are a key neurogenic niche and source of proliferating cells that gives rise to appetite regulatory neurones essential for long-term changes in metabolic physiology $(93,94)$. The idea of cycles of histogenesis underpinning the seasonal response is not new, but a framework to explain photoperiod responses has not been developed (95). Here, we describe a

This article is protected by copyright. All rights reserved. 
mechanistic framework that could explain the photoperiodic regulation of energy balance, but which also has the potential to explain photoperiodic responses more universally.

The basis of the explanation builds on a concept developed from the regulation of energy balance by AgRP neurons in mice. AgRP neurons are an important group of cells in the arcuate nucleus, which contribute to the orexigenic drive (77). Despite this, it is well known that if AgRP neurons are knocked out in the germ line, the phenotype, in terms of food intake, body weight and body composition, appears normal $(96,97)$. It has been interpreted that this lack of phenotype arises because the brain is able to compensate for the lack of AgRP neurons during development (77). However, if the AgRP neurons are destroyed in the adult mouse, both acutely and rapidly, using diptheria toxin targeted specifically to AgRP neurons, then an anorexic phenotype results, with associated weight loss $(96,98)$. These results suggest that the mode and time-course of the knock out is key to determining the phenotypic outcome. In the case of the acute knock out, it is postulated that there is insufficient time for compensatory mechanisms to develop (77). Support for this interpretation was strengthened by an experiment in which AgRP neurons in adult mice were targeted with a knock-out of mitochondrial transcription factor A (TFAM), which causes slow neurodegeneration of the AgRP neurons (99). In this case there was no overt change in either food intake or body weight, suggesting that the slow time-course of neurodegeneration allows mechanisms of compensation to develop. BrdU labelling combined with immunocytochemical phenotyping in this study suggests that the compensatory mechanism involves de novo neurogenesis of AgRP neurons (99). In addition, it is postulated that the TFAM KO-induced neurodegeneration triggers cell proliferation by the neurogenic niche of stem cells in the subventricular zone around the third ventricle. By regulating the balance between neurodegeneration and neurogenesis, it is proposed that the population of AgRP neurons is maintained at a steady level so there are no overall changes to energy balance (99).

This article is protected by copyright. All rights reserved. 
Here we postulate that a similar mechanism may be at the heart of the photoperiodic control of energy balance, and potentially reproduction, in seasonal species. Figure 2 provides a theoretical schematic depicting how such a mechanism might work in terms of the photoperiodic regulation of body weight in the Siberian hamster, based on the recent natural photoperiod evidence from Siberian hamster (48). We propose that a fall in T3, due to a decline in Dio2 expression and subsequently a rise in Dio3 expression, (and potentially a decline in retinoic acid levels predicted by Crbp1 expression), initiates localised apoptosis (e.g. in a small number of the AgRP/NPY), which leads to a slow and progressive reduction in the orexigenic drive. The process of neurodegeneration in turn triggers cell proliferation from the neurogenic niche in the tanycytes. This accounts for the increase in new cells observed under short days. These new cells migrate and differentiate into 'replacement' neurons (e.g. AgRP/NPY) to restore the orexigenic drive. It is important to note that AgRP/NPY cells are an exemplar and that other cell types influencing the orexigenic drive could be critical or additional players might be involved. A key point is that the transition from undifferentiated newly proliferating cells to differentiated cells can occur without the need for a rise in either T3 or retinoic acid hypothalamic levels. This would account for the increase in body weight prior to the change in Dio2 and Crbp1 and this process may also explain photorefractoriness. A key aspect of this hypothetical model is that neither T3 nor retinoic acid are required to drive the physiological process, rather their primary action is to synchronise cycles of apoptosis and proliferation/differentiation of cells involved in a specific physiological outcome (Figure 3). It is only after photoperiod is artificially and abruptly switched from short to long days, that a rapid rise in T3 and retinoic acid levels occurs, which can accelerate the differentiation of the progenitor cells and thereby driving an increase in body weight.

The schematic outlined in Figures 2 and 3 is not just limited to the seasonal regulation of body weight in the Siberian hamster. It also potentially could explain seasonal body weight changes in other species as well as seasonal reproduction, irrespective of whether they are long- or short-day breeders. This is because a key feature of the model is that the phenotype of the apoptosing and

This article is protected by copyright. All rights reserved. 
proliferating cells will determine both the nature and direction of the seasonal response, providing considerable flexibility over the physiological outcome depending on the species. Interestingly, fatemapping studies have shown that neural progenitor cells derived from the hypothalamic ventricular zone can differentiate into a number of phenotypes relevant to energy balance and reproduction, including POMC, NPY and Kisspeptin (100). Thus, the proposed mechanism provides a unifying model that may explain photoperiodic regulation of energy balance and reproduction in species with quite disparate seasonal responses.

This hypothetical model tries to bring together current knowledge into a testable conceptual framework. However, there are some big assumptions that need to be highlighted: 1.) The model depends on increased apoptosis in the hypothalamus during a long to short day transition. There is currently no evidence to support this. 2.) The model requires apoptosis of only a small number of select cells from a target population. Thus a big question is on what basis would such a restricted set of cells be targeted for apoptosis?

\section{Concluding remarks}

Photoperiodic regulation of energy metabolism and reproduction has captured the interest of chronobiologists for many decades (101). The initial discovery of the pars tuberalis as an important centre for the control of photoperiodism increased our understanding of seasonal rhythms (102), but the field saw a significant advance after the discovery of the TSH-deiodinase-T3 retrograde pathway in quail and sheep $(18,19,24)$. Since then, this has been verified in many photoperiodic species including the European, Syrian and Siberian hamsters, the common vole and F344 rats (22, $38,43,103)$.

This article is protected by copyright. All rights reserved. 
While seasonal variation in hypothalamic thyroid hormone signalling seems conserved among photoperiodic species, it results in different phenotypic responses. For example, increased hypothalamic T3 availability in long photoperiod conditions results in reproductive inactivity in short day breeders (sheep) but in reproductive activation in long day breeders (hamster). Other species such as rat and vole breed throughout the year yet show the same thyroid hormone responses to long photoperiods. Likewise, short day induces body weight loss in Siberian hamsters, but causes body weight gain in Syrian hamsters despite similarities in the hypothalamic thyroid pathway $(2,6)$. Thus, interspecies conservation of photoperiodism ends with T3 induction and subsequent physiological responses are diverse and reflect the adaptive needs of each species. While the importance of thyroid hormone signalling cannot be underestimated, it alone cannot explain the divergence of downstream physiological events amongst different species.

Recent years has brought a renewed focus on the role and function of tanycytes as the corridor of communication between the hypothalamus and PT of the pituitary gland $(30,31)$. Many pathways have been found to be photoperiodically regulated in tanycytes (22) and their role in photoperiodic control cannot be ignored. Most importantly, retinoic acid and Wnt/ $\beta$-catenin signalling have been found in Siberian hamster and F344 rats with the most prominent changes similar to thyroid hormone signalling $(61,104)$. But new players also include a previously unrecognised role for inflammatory signals in the healthy brain $(55,71)$. Together, these findings highlight the complexity that underlie phenotypic variations in the response to photoperiod between species.

The one unifying response amongst different species seems to be cell proliferation/neurogenesis. Findings in sheep, hamster and F344 rats point to a potential photoperiodic shift in cell proliferation/neurogenesis $(50,88,89,91)$ and this has the potential to explain the striking variation in seasonal phenotype among photoperiodic species. The hypothesis that cell division may be important for seasonal timing is based on the neurogenic potential of tanycytes and the fact that they are the locus of striking seasonal morphological changes $(32,33,35,105)$. It will be intriguing to

This article is protected by copyright. All rights reserved. 
test in future whether hypothalamic neurogenesis can bring the photoperiodic response together and will provide a fundamental insight into the common basis of physiological outcomes in energy balance and reproduction.

Table 1: Evidence for photoperiodic changes in hypothalamic cell proliferation in seasonal species.

\begin{tabular}{|c|c|c|c|}
\hline Species & $\begin{array}{l}\text { Reproductive } \\
\text { response }\end{array}$ & Evidence & Reference (s) \\
\hline Hamster & & & \\
\hline $\begin{array}{l}\text { male Syrian } \\
\text { (golden) hamster }\end{array}$ & long-day breeder & $\begin{array}{l}\text { BrdU labelling increases after } \\
\text { transition from long to short day }\end{array}$ & (87) \\
\hline $\begin{array}{l}\text { male Siberian } \\
\text { hamster }\end{array}$ & long-day breeder & $\begin{array}{l}\text { Nestin expression } \\
\text { is down-regulated in short day }\end{array}$ & $(52,66)$ \\
\hline
\end{tabular}

\section{Sheep}

male Soay sheep short-day breeder Increased number of BrdU labelled cells in short day compared to long day

Ile-de France ewes short-day breeder BrdU labelling is higher in short day

Increased rate of DCX-expressing neurons in short day

Pinealectomy affects cell proliferation; DCX-labelling is decreased after Ara-C administration.

Photoperiod and thyoid hormone regulates Dct, a tanycyte marker implicated in neural progenitor cell proliferation.

Rat

male F344 rat can breed in short

Ki57 labelling increased in short day vs and long day long day

This article is protected by copyright. All rights reserved. 


\section{Figure legends}

Figure 1: Orchestration of gene expression across the seasons in Siberian hamster held in natural ambient photoperiod and temperature. Gene expression profiles for Dio2, Dio3 and MCT8 (upper panel) and Nestin, Vimentin, Crbp1 (lower panel) in the hypothalamus of Siberian hamsters in natural photoperiod over two consecutive years is shown. Upper and lower left panels show summer to winter transition and upper and lower right panels show winter to summer transition. Gene expression was determined by quantitative in situ hybridisation. Also shown are the ambient natural photoperiod (yellow line) and body weights of hamsters (black dots). $\mathrm{N}=6-7$ animals per timepoint. Data are redrawn from Petri et al. (48).

Figure 2: Hypothetical mechanism for seasonal control of body weight based on predicted T3 and RA levels in the hypothalamus. The lower figure shows a schematic representation of body weight cycles in Siberian hamsters over two annual cycles, together with time-dependent changes in Dio2 and Crbp1 gene expression, predicting changes in T3 and RA levels, respectively. Data are extrapolated from Figure 1. The upper figure depicts the changes in apoptosis and regeneration of neurons associated with energy balance within the arcuate nucleus (ARC) and ventromedial nucleus (VMN) of the hypothalamus with time in the annual body weight cycles.

(1) Hamsters are at maximal body weight with a full complement of hypothalamic neurons controlling energy balance. (2) \& (3) Fall in T3 (and RA) triggers progressive neurodegeneration and cell loss within a small sub-set of energy balance critical neurons, which reduces orexigenic drive and results in loss of body weight. (4) Neurodegeneration induces compensatory proliferation of progenitor cells from the neurogenic niche in the ventricular zone. (5) \& (6) Progenitor cells differentiate into new neurons involved in control of energy balance which progressively restores maximal orexigenic drive and body weight (7). $3 \mathrm{~V}=$ third ventricle, $\mathrm{ME}=$ median eminence, $\mathrm{RA}=$ retinoic acid

This article is protected by copyright. All rights reserved. 
Figure 3: Summary schematic depicting the interrelationship between TSH-stimulated thyroid hormone, neuronal degeneration, cell proliferation and re-modelling providing a hypothetical basis for seasonal control of energy balance and reproduction, through cyclic changes in sub-sets of specific hypothalamic neurons. It is proposed that seasonal changes in physiology are related to a changing proportion of specific neurons which results in a response across the season. These are controlled through two interacting cycles, one of thyroid hormone synthesis and metabolism and the other of neurodegeneration/neurogenesis. Photoperiod, through melatonin, regulates the production of TSH and potentially other signals (e.g. NMU in the F344 rat), which in turn regulates seasonal cycles of thyroid hormone synthesis and metabolism. In some seasonal species (e.g. Siberian hamster and F344 rat) this may also include seasonal cycles in retinoic acid metabolism. It is hypothesised that a fall in T3 levels triggers apoptosis in a small fraction of key neurons involved in energy balance and reproduction, which in turn alters physiological status (e.g. body weight, testes size). The loss of key neurons then triggers compensatory cell proliferation from progenitor cells within the neurogenic niche of the hypothalamus, which through differentiation and other structural changes in tanycyctes (e.g. vimentin expression) ultimately restores the population of neurons regulating energy balance and reproduction to their maximal level. These underpinning changes allow the corresponding physiological status also to be restored.

\section{Acknowlegdements}

We thank Pat Bain for help in preparing the figures. The authors are supported by the Scottish Government (PJM and PB), BBSRC (BB/K001043/1) (PJM and GH), MRC (MR/P012205/1) (PJM) and The Physiological Society (GH). The authors declare that they have no conflicts of interst.

This article is protected by copyright. All rights reserved. 


\section{References}

1. Ebling FJ, Barrett P. The regulation of seasonal changes in food intake and body weight. $J$ Neuroendocrinol. 2008; 20(6): 827-33.

2. Lincoln GA, Short RV. Seasonal breeding: nature's contraceptive. Recent Prog Horm Res. 1980; 36( 36): 1-52.

3. Dardente H, Lomet D, Robert V, Decourt C, Beltramo M, Pellicer-Rubio MT. Seasonal breeding in mammals: From basic science to applications and back. Theriogenology. 2016; 86(1): 324-32.

4. Lincoln GA, Richardson M. Photo-neuroendocrine control of seasonal cycles in body weight, pelage growth and reproduction: lessons from the HPD sheep model. Comp Biochem Physiol C Pharmacol Toxicol Endocrinol. 1998; 119(3): 283-94.

5. Bartness TJ, Wade GN. Photoperiodic control of body weight and energy metabolism in Syrian hamsters (Mesocricetus auratus): role of pineal gland, melatonin, gonads, and diet. Endocrinology. 1984; 114(2): 492-8.

6. Lewis JE, Ebling F. Hamsters as model species for neuroendocrine studies. In: Ludwig M, Levkowitz G, eds. Model animals in neuroendocrinology: From worm to mouse to man: WileyBlackwell 2018: 464.

7. Bartness TJ, Powers JB, Hastings MH, Bittman EL, Goldman BD. The timed infusion paradigm for melatonin delivery: what has it taught us about the melatonin signal, its reception, and the photoperiodic control of seasonal responses? J Pineal Res. 1993; 15(4): 161-90.

8. Morgan PJ, Barrett P, Howell HE, Helliwell R. Melatonin receptors: localization, molecular pharmacology and physiological significance. Neurochem Int. 1994; 24(2): 101-46.

This article is protected by copyright. All rights reserved. 
9. Weaver DR, Provencio I, Carlson LL, Reppert SM. Melatonin receptors and signal transduction in photorefractory Siberian hamsters (Phodopus sungorus). Endocrinology. 1991; 128(2): 1086-92.

10. Pengelley ET, Fisher KC. Onset and Cessation of Hibernation under Constant Temperature and Light in the Golden-mantled Ground Squirrel (Citellus lateralis). Nature. 1957; 180(4598): 13712.

11. Helm B, Ben-Shlomo R, Sheriff MJ, Hut RA, Foster R, Barnes BM, Dominoni D. Annual rhythms that underlie phenology: biological time-keeping meets environmental change. Proc Biol Sci. 2013; 280(1765): 20130016.

12. Gwinner E. Circannual rhythms Berlin Heidelberg: Springer-Verlag 1986.

13. Saenz de MC, Monecke S, Bartzen-Sprauer J, Laran-Chich MP, Pevet P, Hazlerigg DG, Simonneaux V. A circannual clock drives expression of genes central for seasonal reproduction. Curr Biol. 2014; 24(13): 1500-6.

14. Williams LM, Morgan PJ. Demonstration of melatonin-binding sites on the pars tuberalis of the rat. J Endocrinol. 1988; 119(1): R1-3.

15. Wittkowski W, Bergmann M, Hoffmann K, Pera F. Photoperiod-dependent changes in TSHlike immunoreactivity of cells in the hypophysial pars tuberalis of the Djungarian hamster, Phodopus sungorus. Cell Tissue Res. 1988; 251(1): 183-7.

16. Bockers TM, Niklowitz P, Bockmann J, Fauteck JD, Wittkowski W, Kreutz MR. Daily melatonin injections induce cytological changes in pars tuberalis-specific cells similar to short photoperiod. J Neuroendocrinol. 1995; 7(8): 607-13.

This article is protected by copyright. All rights reserved. 
17. Bockmann J, Bockers TM, Vennemann B, Niklowitz P, Muller J, Wittkowski W, Sabel B, Kreutz MR. Short photoperiod-dependent down-regulation of thyrotropin-alpha and -beta in hamster pars tuberalis-specific cells is prevented by pinealectomy. Endocrinology. 1996; 137(5): 1804-13.

18. Yoshimura T, Yasuo S, Watanabe M, ligo M, Yamamura T, Hirunagi K, Ebihara S. Lightinduced hormone conversion of T4 to T3 regulates photoperiodic response of gonads in birds. Nature. 2003; 426(6963): 178-81.

19. Nakao N, Ono H, Yamamura T, Anraku T, Takagi T, Higashi K, Yasuo S, Katou Y, Kageyama S, Uno Y, Kasukawa T, ligo M, Sharp PJ, Iwasawa A, Suzuki Y, Sugano S, Niimi T, Mizutani M, Namikawa T, Ebihara S, Ueda HR, Yoshimura T. Thyrotrophin in the pars tuberalis triggers photoperiodic response. Nature. 2008; 452(7185): 317-22.

20. Wood SH, Christian HC, Miedzinska K, Saer BR, Johnson M, Paton B, Yu L, McNeilly J, Davis JR, McNeilly AS, Burt DW, Loudon AS. Binary switching of calendar cells in the pituitary defines the phase of the circannual cycle in mammals. Curr Biol. 2015; 25(20): 2651-62.

21. Dardente H, Wyse CA, Birnie MJ, Dupre SM, Loudon AS, Lincoln GA, Hazlerigg DG. A molecular switch for photoperiod responsiveness in mammals. Curr Biol. 2010; 20(24): 2193-8.

22. Ross AW, Helfer G, Russell L, Darras VM, Morgan PJ. Thyroid hormone signalling genes are regulated by photoperiod in the hypothalamus of F344 rats. PLoS One. 2011; 6(6): e21351.

23. Ross AW, Russell L, Helfer G, Thomson LM, Dalby MJ, Morgan PJ. Photoperiod regulates lean mass accretion, but not adiposity, in growing F344 rats fed a high fat diet. PLoS One. 2015; 10(3): e0119763.

24. Hanon EA, Lincoln GA, Fustin JM, Dardente H, Masson-Pevet M, Morgan PJ, Hazlerigg DG. Ancestral TSH mechanism signals summer in a photoperiodic mammal. Curr Biol. 2008; 18(15): 114752.

This article is protected by copyright. All rights reserved. 
25. Bolborea M, Helfer G, Ebling FJ, Barrett P. Dual signal transduction pathways activated by TSH receptors in rat primary tanycyte cultures. J Mol Endocrinol. 2015; 54(3): 241-50.

26. Ikegami K, Liao X-H, Hoshino Y, Ono H, Ota W, Ito Y, Nishiwaki-Ohkawa T, Sato C, Kitajima K, ligo M, Shigeyoshi Y, Yamada M, Murata Y, Refetoff S, Yoshimura T. Tissue-specific posttranslational modification allows functional targeting of thyrotropin. Cell Reports. 2014; 9(3): 801-9.

27. Helfer G, Ross AW, Morgan PJ. Neuromedin U partly mimics thyroid-stimulating hormone and triggers $W n t / \beta$-Catenin signalling in the photoperiodic response of F344 rats. J Neuroendocrinol. 2013; 25(12): 1264-72.

28. Aizawa S, Sakata I, Nagasaka M, Higaki Y, Sakai T. Negative regulation of neuromedin U mRNA expression in the rat pars tuberalis by melatonin. PLoS One. 2013; 8(7): e67118.

29. Helfer G, Ross AW, Russell L, Thomson LM, Shearer KD, Goodman TH, McCaffery PJ, Morgan PJ. Photoperiod regulates Vitamin A and Wnt/ $\beta$-Catenin signaling in F344 rats. Endocrinology. 2012; 153(2): 815-24.

30. Ebling FJP, Lewis JE. Tanycytes and hypothalamic control of energy metabolism. Glia. 2018; 66(6): 1176-84.

31. Prevot V, Dehouck B, Sharif A, Ciofi P, Giacobini P, Clasadonte J. The versatile tanycyte: A hypothalamic integrator of reproduction and energy metabolism. Endocr Rev. 2018; 39(3): 333-68.

32. Bolborea M, Laran-Chich MP, Rasri K, Hildebrandt H, Govitrapong P, Simonneaux V, Pevet P, Steinlechner S, Klosen P. Melatonin controls photoperiodic changes in tanycyte vimentin and neural cell adhesion molecule expression in the Djungarian hamster (Phodopus sungorus). Endocrinology. 2011; 152(10): 3871-83.

This article is protected by copyright. All rights reserved. 
33. Migaud M, Butrille L, Batailler M. Seasonal regulation of structural plasticity and neurogenesis in the adult mammalian brain: focus on the sheep hypothalamus. Front Neuroendocrinol. 2015; 37: 146-57.

34. Kameda Y, Arai Y, Nishimaki T. Ultrastructural localization of vimentin immunoreactivity and gene expression in tanycytes and their alterations in hamsters kept under different photoperiods. Cell Tissue Res. 2003; 314(2): 251-62.

35. Helfer G, Ross AW, Thomson LM, Mayer CD, Stoney PN, McCaffery PJ, Morgan PJ. A neuroendocrine role for chemerin in hypothalamic remodelling and photoperiodic control of energy balance. Sci Rep. 2016; May 26(6): 26830.

36. Kohrle J. Local activation and inactivation of thyroid hormones: the deiodinase family. Mol Cell Endocrinol. 1999; 151(1-2): 103-19.

37. Saenz de MC, Hanon EA, Dardente H, Birnie M, Simonneaux V, Lincoln GA, Hazlerigg DG. Circannual variation in thyroid hormone deiodinases in a short-day breeder. J Neuroendocrinol. 2013; 25(4): 412-21.

38. Hanon EA, Routledge K, Dardente H, Masson-Pevet M, Morgan PJ, Hazlerigg DG. Effect of photoperiod on the TSH neuroendocrine system in the European hamster (Cricetus cricetus). $J$ Neuroendocrinol. 2009; 22(1): 55-5.

39. Barrett P, Ebling FJP, Schuhler S, Wilson D, Ross AW, Warner A, Jethwa P, Boelen A, Visser TJ, Ozanne DM, Archer ZA, Mercer JG, Morgan PJ. Hypothalamic thyroid hormone catabolism acts as a gatekeeper for the seasonal control of body weight and reproduction. Endocrinology. 2007; 148(8): 3608-17.

This article is protected by copyright. All rights reserved. 
40. Herwig A, Wilson D, Logie TJ, Boelen A, Morgan PJ, Mercer JG, Barrett P. Photoperiod and acute energy deficits interact on components of the thyroid hormone system in hypothalamic tanycytes of the Siberian hamster. Am J Physiol Regul Integr Comp Physiol. 2009; 296(5): R1307-15.

41. Prendergast BJ, Pyter LM, Kampf-Lassin A, Patel PN, Stevenson TJ. Rapid induction of hypothalamic iodothyronine deiodinase expression by photoperiod and melatonin in juvenile Siberian hamsters (Phodopus sungorus). Endocrinology. 2013; 154(2): 831-41.

42. Revel FG, Saboureau M, Pevet P, Mikkelsen JD, Simonneaux V. Melatonin regulates type 2 deiodinase gene expression in the Syrian hamster. Endocrinology. 2006; 147(10): 4680-7.

43. Krol E, Douglas A, Dardente H, Birnie MJ, Vinne Vvd, Eijer WG, Gerkema MP, Hazlerigg DG, Hut RA. Strong pituitary and hypothalamic responses to photoperiod but not to 6-methoxy-2benzoxazolinone in female common voles (Microtus arvalis). Gen Comp Endocrinol. 2012; 179(2): 289-95.

44. Segerson TP, Kauer J, Wolfe HC, Mobtaker H, Wu P, Jackson IM, Lechan RM. Thyroid hormone regulates TRH biosynthesis in the paraventricular nucleus of the rat hypothalamus. Science. 1987; 238(4823): 78-80.

45. Ebling FJ, Wilson D, Wood J, Hughes D, Mercer JG, Morgan PJ, Barrett P. The thyrotropinreleasing hormone secretory system in the hypothalamus of the Siberian hamster in long and short photoperiods. J Neuroendocrinol. 2008; 20(5): 576-86.

46. Friesema EC, Jansen J, Jachtenberg JW, Visser WE, Kester MH, Visser TJ. Effective cellular uptake and efflux of thyroid hormone by human monocarboxylate transporter 10. Mol Endocrinol. 2008; 22(6): 1357-69.

This article is protected by copyright. All rights reserved. 
47. Sugiyama $D$, Kusuhara $H$, Taniguchi $H$, Ishikawa $S$, Nozaki $Y$, Aburatani $H$, Sugiyama $Y$. Functional characterization of rat brain-specific organic anion transporter (Oatp14) at the bloodbrain barrier: high affinity transporter for thyroxine. J Biol Chem. 2003; 278(44): 43489-95.

48. Petri I, Diedrich V, Wilson D, Fernandez-Calleja J, Herwig A, Steinlechner S, Barrett P. Orchestration of gene expression across the seasons: Hypothalamic gene expression in natural photoperiod throughout the year in the Siberian hamster. Sci Rep. 2016; 6: 29689.

49. Heideman PD, Sylvester CJ. Reproductive photoresponsiveness in unmanipulated male Fischer 344 laboratory rats. Biol Reprod. 1997; 57(1): 134-8.

50. Shearer KD, Stoney PN, Nanescu SE, Helfer G, Barrett P, Ross AW, Morgan PJ, McCaffery P. Photoperiodic expression of two RALDH enzymes and the regulation of cell proliferation by retinoic acid in the rat hypothalamus. J Neurochem. 2012; 122(4): 789-99.

51. Ross AW, Webster CA, Mercer JG, Moar KM, Ebling FJ, Schuhler S, Barrett P, Morgan PJ. Photoperiodic regulation of hypothalamic retinoid signaling: association of retinoid $\mathrm{X}$ receptor gamma with body weight. Endocrinology. 2004; 145(1): 13-20.

52. Barrett P, Ivanova E, Graham ES, Ross AW, Wilson D, Ple H, Mercer JG, Ebling FJ, Schuhler S, Dupre SM, Loudon A, Morgan PJ. Photoperiodic regulation of cellular retinol binding protein, CRBP1 [corrected] and nestin in tanycytes of the third ventricle ependymal layer of the Siberian hamster. J Endocrinol. 2006; 191(3): 687-98.

53. Bank JHH, Wilson D, Rijntjes E, Barrett P, Herwig A. Alternation between short- and long photoperiod reveals hypothalamic gene regulation linked to seasonal body weight changes in Djungarian hamsters (Phodopus sungorus). J Neuroendocrinol. 2017; 29(7).

54. Stoney PN, Helfer G, Rodrigues D, Morgan PJ, McCaffery P. Thyroid hormone activation of retinoic acid synthesis in hypothalamic tanycytes. Glia. 2016; 64(3): 425-39.

This article is protected by copyright. All rights reserved. 
55. Helfer G, Wu QF. Chemerin: a multifaceted adipokine involved in metabolic disorders. J Endocrinol. 2018; 238(2): R79-R94.

56. Lomet D, Cognie J, Chesneau D, Dubois E, Hazlerigg D, Dardente H. The impact of thyroid hormone in seasonal breeding has a restricted transcriptional signature. Cell Mol Life Sci. 2018; 75(5): 905-19.

57. Lewis JE, Ebling FJ. Tanycytes as regulators of seasonal cycles in neuroendocrine function. Front Neurol. 2017; 8(79): 1-7.

58. Tavolaro FM, Thomson LM, Ross AW, Morgan PJ, Helfer G. Photoperiodic effects on seasonal physiology, reproductive status and hypothalamic gene expression in young male F344 rats. J Neuroendocrinol. 2015; 27(2): 79-87.

59. Boucsein A, Benzler J, Hempp C, Stohr S, Helfer G, Tups A. Photoperiodic and Diurnal Regulation of WNT Signaling in the Arcuate Nucleus of the Female Djungarian Hamster, Phodopus sungorus. Endocrinology. 2016; 157(2): 799-809.

60. Jacobs S, Lie DC, DeCicco KL, Shi Y, DeLuca LM, Gage FH, Evans RM. Retinoic acid is required early during adult neurogenesis in the dentate gyrus. Proc Natl Acad Sci USA. 2006; 103(10): 3902-7.

61. Helfer G, Tups A. Hypothalamic Wnt signalling and its role in energy balance regulation. J Neuroendocrinol. 2016; 28(3): 12368.

62. Batailler M, Mullier A, Sidibe A, Delagrange P, Prevot V, Jockers R, Migaud M. Neuroanatomical distribution of the orphan GPR50 receptor in adult sheep and rodent brains. J Neuroendocrinol. 2012; 24(5): 798-808.

63. Reppert SM, Weaver DR, Ebisawa T, Mahle CD, Kolakowski LF, Jr. Cloning of a melatoninrelated receptor from human pituitary. FEBS Lett. 1996; 386(2-3): 219-24.

This article is protected by copyright. All rights reserved. 
64. Drew JE, Barrett P, Williams LM, Conway S, Morgan PJ. The ovine melatonin-related receptor: cloning and preliminary distribution and binding studies. J Neuroendocrinol. 1998; 10(9): 651-61.

65. Bank JHH, Cubuk C, Wilson D, Rijntjes E, Kemmling J, Markovsky H, Barrett P, Herwig A. Gene expression analysis and microdialysis suggest hypothalamic triiodothyronine (T3) gates daily torpor in Djungarian hamsters (Phodopus sungorus). J Comp Physiol B. 2017; 187(5-6): 857-68.

66. Herwig A, de Vries EM, Bolborea M, Wilson D, Mercer JG, Ebling FJ, Morgan PJ, Barrett P. Hypothalamic ventricular ependymal thyroid hormone deiodinases are an important element of circannual timing in the Siberian hamster (Phodopus sungorus). PLoS One. 2013; 8(4): e62003.

67. Bechtold DA, Sidibe A, Saer BR, Li J, Hand LE, Ivanova EA, Darras VM, Dam J, Jockers R, Luckman SM, Loudon AS. A role for the melatonin-related receptor GPR50 in leptin signaling, adaptive thermogenesis, and torpor. Curr Biol. 2012; 22(1): 70-7.

68. Stevenson TJ. Environmental and hormonal regulation of epigenetic enzymes in the hypothalamus. J Neuroendocrinol. 2017; 29(5): 1-9.

69. Stevenson TJ, Prendergast BJ. Reversible DNA methylation regulates seasonal photoperiodic time measurement. Proc Natl Acad Sci U S A. 2013; 110(41): 16651-56.

70. Lynch EW, Coyle CS, Lorgen M, Campbell EM, Bowman AS, Stevenson TJ. Cyclical DNA methyltransferase 3a expression is a seasonal and estrus timer in reproductive tissues. Endocrinology. 2016; 157(6): 2469-78.

71. Stoney PN, Rodrigues D, Helfer G, Khatib T, Ashton A, Hay EA, Starr R, Kociszewska D, Morgan P, McCaffery P. A seasonal switch in histone deacetylase gene expression in the hypothalamus and their capacity to modulate nuclear signaling pathways. Brain Behav Immun. 2017; $\operatorname{Mar}(61): 340-52$.

This article is protected by copyright. All rights reserved. 
72. Stevenson TJ. Circannual and circadian rhythms of hypothalamic DNA methyltransferase and histone deacetylase expression in male Siberian hamsters (Phodopus sungorus). Gen Comp Endocrinol. 2017; Mar (243): 130-7.

73. Stevenson TJ, Onishi KG, Bradley SP, Prendergast BJ. Cell-autonomous iodothyronine deiodinase expression mediates seasonal plasticity in immune function. Brain Behav Immun. 2014; Feb(36): 61-70.

74. Fonken LK, Bedrosian TA, Michaels HD, Weil ZM, Nelson RJ. Short photoperiods attenuate central responses to an inflammogen. Brain Behav Immun. 2012; 26(4): 617-22.

75. Banks R, Delibegovic M, Stevenson TJ. Photoperiod- and triiodothyronine-dependent regulation of reproductive neuropeptides, proinflammatory cytokines, and peripheral physiology in Siberian hamsters (Phodopus sungorus). J Biol Rhythms. 2016; 31(3): 299-307.

76. Nakane Y, Yoshimura T. Universality and diversity in the signal transduction pathway that regulates seasonal reproduction in vertebrates. Front Neurosci. 2014; 8(115).

77. Webber ES, Bonci A, Krashes MJ. The elegance of energy balance: Insight from circuit-level manipulations. Synapse. 2015; 69(9): 461-74.

78. Balland E, Dam J, Langlet F, Caron E, Steculorum S, Messina A, Rasika S, Falluel-Morel A, Anouar Y, Dehouck B, Trinquet E, Jockers R, Bouret S, Prevot V. Hypothalamic tanycytes are an ERKgated conduit for leptin into the brain. Cell Metab. 2014; 19(2): 293-301.

79. Ross AW, Johnson CE, Bell LM, Reilly L, Duncan JS, Barrett P, Heideman PD, Morgan PJ. Divergent regulation of hypothalamic neuropeptide $Y$ and agouti-related protein by photoperiod in F344 rats with differential food intake and growth. J Neuroendocrinol. 2009; 21(7): 610-9.

This article is protected by copyright. All rights reserved. 
80. Wittmann G, Farkas E, Szilvasy-Szabo A, Gereben B, Fekete C, Lechan RM. Variable proopiomelanocortin expression in tanycytes of the adult rat hypothalamus and pituitary stalk. $J$ Comp Neurol. 2017; 525(3): 411-41.

81. Coppola A, Liu ZW, Andrews ZB, Paradis E, Roy MC, Friedman JM, Ricquier D, Richard D, Horvath TL, Gao XB, Diano S. A central thermogenic-like mechanism in feeding regulation: an interplay between arcuate nucleus T3 and UCP2. Cell Metab. 2007; 5(1): 21-33.

82. Clarke IJ, Rao A, Chilliard Y, Delavaud C, Lincoln GA. Photoperiod effects on gene expression for hypothalamic appetite-regulating peptides and food intake in the ram. Am J Physiol Regul Integr Comp Physiol. 2003; 284(1): R101-15.

83. Mercer JG, Moar KM, Ross AW, Hoggard N, Morgan PJ. Photoperiod regulates arcuate nucleus POMC, AGRP, and leptin receptor mRNA in Siberian hamster hypothalamus. Am J Physiol Regul Integr Comp Physiol. 2000; 278(1): R271-81.

84. Mercer JG, Moar KM, Logie TJ, Findlay PA, Adam CL, Morgan PJ. Seasonally inappropriate body weight induced by food restriction: effect on hypothalamic gene expression in male Siberian hamsters. Endocrinology. 2001; 142(10): 4173-81.

85. Reddy AB, Cronin AS, Ford H, Ebling FJP. Seasonal regulation of food intake and body weight in the male Siberian hamster: studies of hypothalamic orexin (hypocretin), neuropeptide Y (NPY) andpro-opiomelanocortin (POMC). Eur J Neurosci. 1999; 11(9): 3255-64.

86. Levy F, Batailler M, Meurisse M, Migaud M. Adult neurogenesis in sheep: Characterization and contribution to reproduction and behavior. Front Neurosci. 2017; 11(570): 1-15.

87. Huang L, DeVries GJ, Bittman EL. Photoperiod regulates neuronal bromodeoxyuridine labeling in the brain of a seasonally breeding mammal. J Neurobiol. 1998; 36(3): 410-20.

This article is protected by copyright. All rights reserved. 
88. Migaud M, Batailler M, Pillon D, Franceschini I, Malpaux B. Seasonal changes in cell proliferation in the adult sheep brain and pars tuberalis. J Biol Rhythms. 2011; 26(6): 486-96.

89. Hazlerigg DG, Wyse CA, Dardente H, Hanon EA, Lincoln GA. Photoperiodic variation in CD45positive cells and cell proliferation in the mediobasal hypothalamus of the Soay sheep. Chronobiol Int. 2013; 30(4): 548-58.

90. Dardente H, Lomet D. Photoperiod and thyroid hormone regulate expression of Idopachrome tautomerase (Dct), a melanocyte stem-cell marker, in tanycytes of the ovine hypothalamus. J Neuroendocrinol. 2018; 30(9): e12640.

91. Batailler M, Chesneau D, Derouet L, Butruille L, Segura S, Cognie J, Dupont J, Pillon D, Migaud M. Pineal-dependent increase of hypothalamic neurogenesis contributes to the timing of seasonal reproduction in sheep. Sci Rep. 2018; 8(1): 6188.

92. Wittmann G, Lechan RM. Prss56 expression in the rodent hypothalamus: Inverse correlation with pro-opiomelanocortin suggests oscillatory gene expression in adult rat tanycytes. J Comp Neurol. 2018; 526(15): 2444-61.

93. Kokoeva MV, Yin H, Flier JS. Neurogenesis in the hypothalamus of adult mice: potential role in energy balance. Science. 2005; 310(5748): 679-83.

94. Lee DA, Bedont JL, Pak T, Wang H, Song J, Miranda-Angulo A, Takiar V, Charubhumi V, Balordi F, Takebayashi H, Aja S, Ford E, Fishell G, Blackshaw S. Tanycytes of the hypothalamic median eminence form a diet-responsive neurogenic niche. Nat Neurosci. 2012; 15(5): 700-2.

95. Hazlerigg DG, Lincoln GA. Hypothesis: cyclical histogenesis is the basis of circannual timing. J Biol Rhythms. 2011; 26(6): 471-85.

96. Luquet S, Perez FA, Hnasko TS, Palmiter RD. NPY/AgRP neurons are essential for feeding in adult mice but can be ablated in neonates. Science. 2005; 310(5748): 683-5.

This article is protected by copyright. All rights reserved. 
97. Qian S, Chen H, Weingarth D, Trumbauer ME, Novi DE, Guan XM, Yu H, Shen Z, Feng Y, Frazier E, Chen AR, Camacho RE, Shearman LP, Gopal-Truter S, MacNeil DJ, Van der Ploeg LHT, Marsh DJ. Neither agouti-related protein nor neuropeptide $\mathrm{Y}$ is critically required for the regulation of energy homeostasis in mice. Mol Cell Biol. 2002; 22(14): 5027-35.

98. Gropp E, Shanabrough M, Borok E, Xu AW, Janoschek R, Buch T, Plum L, Balthasar N, Hampel B, Waisman A, Barsh GS, Horvath TL, Brüning JC. Agouti-related peptide-expressing neurons are mandatory for feeding. Nat Neurosci. 2005; 8(10): 1289.

99. Pierce AA, Xu AW. De Novo Neurogenesis in Adult Hypothalamus as a Compensatory Mechanism to Regulate Energy Balance. J Neurosci. 2010; 30(2): 723-30.

100. Toda C, Santoro A, Kim JD, Diano S. POMC neurons: From birth to death. Annu Rev Physiol. 2017; Feb 10(79): 209-36.

101. Dardente H, Hazlerigg DG, Ebling FJ. Thyroid hormone and seasonal rhythmicity. Front Endocrinol 2014; 5(19): 19.

102. Morgan PJ, Williams LM. The pars tuberalis of the pituitary: a gateway for neuroendocrine output. Rev Reprod. 1996; 1(3): 153-61.

103. Yasuo S, Yoshimura T, Ebihara S, Korf HW. Photoperiodic control of TSH-beta expression in the mammalian pars tuberalis has different impact on the induction and suppression of the hypothalamo-hypopysial gonadal axis. J Neuroendocrinol. 2009; 22(1): 43-50.

104. Ransom J, Morgan PJ, McCaffery PJ, Stoney PN. The rhythm of retinoids in the brain. J Neurochem. 2014; 129(3): 366-76.

105. Batailler M, Derouet L, Butruille L, Migaud M. Sensitivity to the photoperiod and potential migratory features of neuroblasts in the adult sheep hypothalamus. Brain Struct Funct. 2015; 221(6): $1-14$.

This article is protected by copyright. All rights reserved. 
106. Batailler M, Droguerre M, Baroncini M, Fontaine C, Prevot V, Migaud M. DCX-expressing cells in the vicinity of the hypothalamic neurogenic niche: a comparative study between mouse, sheep, and human tissues. J Comp Neurol. 2014; 522(8): 1966-85.

This article is protected by copyright. All rights reserved. 

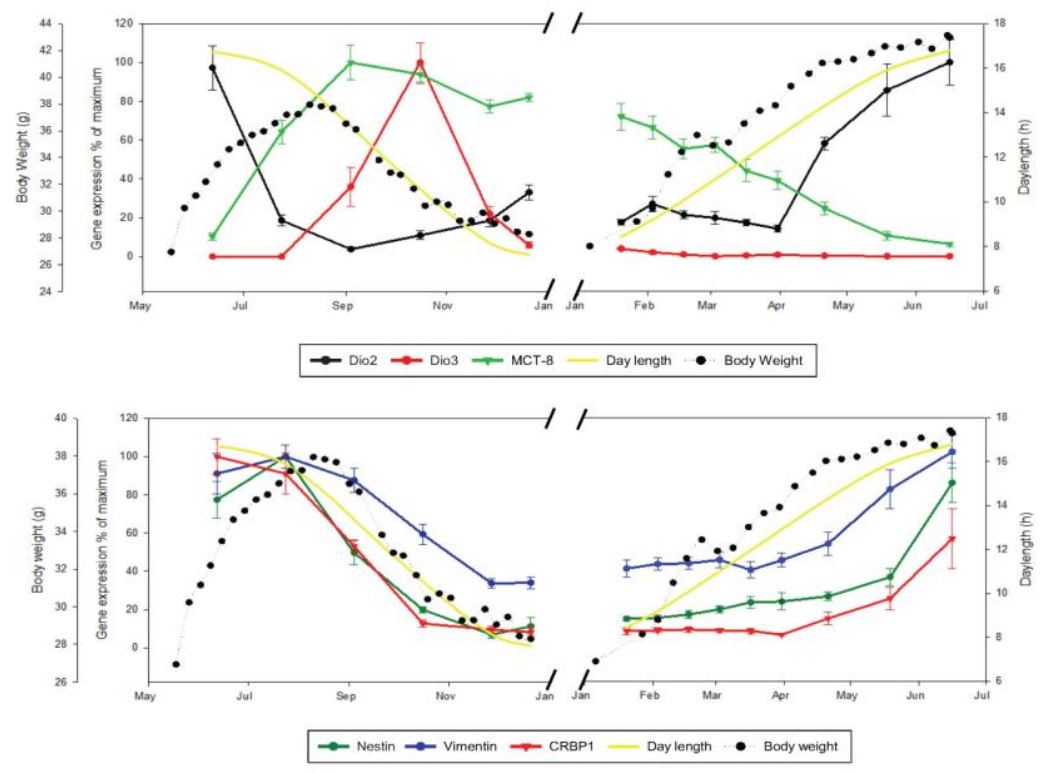

This article is protected by copyright. All rights reserved. 

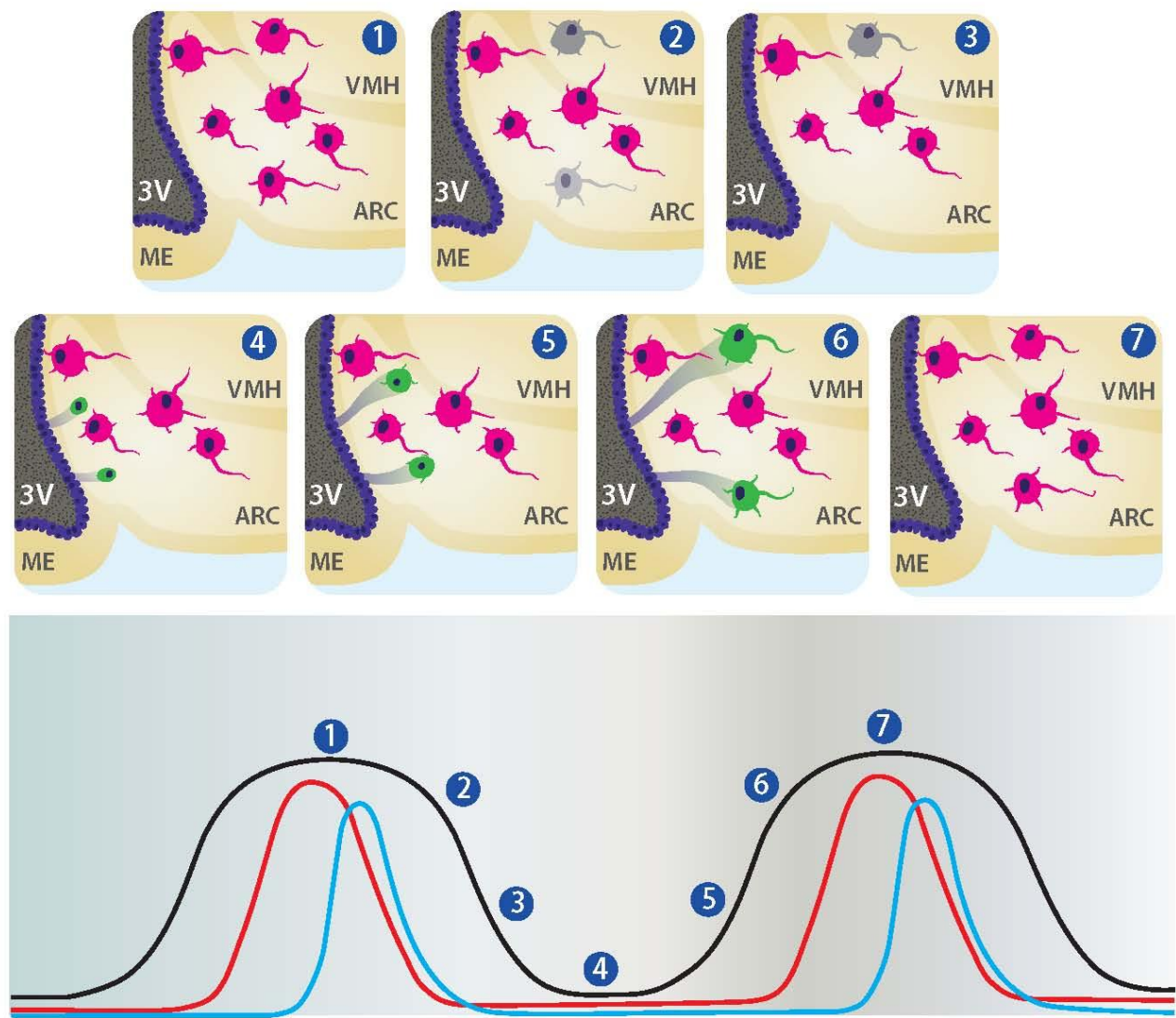

Body weight $=\quad$ DlO2 expression (T3) $-\quad$ CRBP1 expression (RA) $=$

This article is protected by copyright. All rights reserved. 


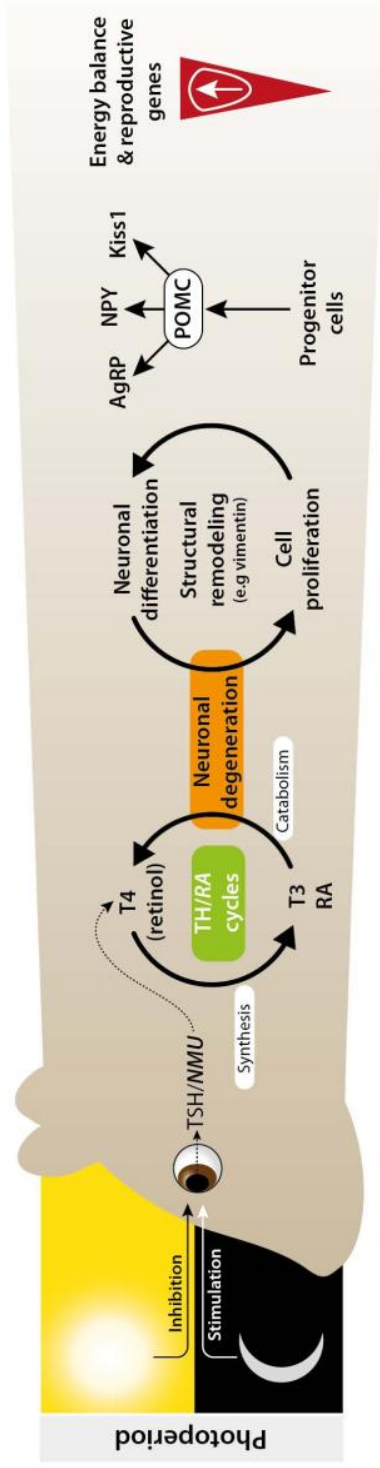

This article is protected by copyright. All rights reserved. 